\title{
Pelvic-floor-muscle-training adherence "modifiers": A review of primary qualitative studies-2011 ICS State-of-the-Science Seminar research paper III of IV
}

\author{
Authors \\ Jean Hay-Smith, \\ Sarah Dean, \\ Kathryn Burgio, \\ Doreen McClurg, \\ Helena Frawley, \\ Chantale Dumoulin \\ Conflicts of interest: None.
}

Correspondence to: Jean Hay-Smith, Department of Women's and Children's Health, Dunedin School of Medicine, University of Otago, PO Box 913, Dunedin 9054, New Zealand.

E-mail: jean.hay-smith@otago.ac.nz

\section{Abstract}

Aims

This review aims to locate and summarize the findings of qualitative studies exploring the experience of and adherence to pelvic floor muscle training (PFMT) to recommend future directions for practice and research.

Methods

Primary qualitative studies were identified through a conventional subject search of electronic databases, reference-list checking, and expert contact. A core eligibility criterion was the inclusion of verbatim quotes from participants about PFMT experiences. Details of study aims, methods, and participants were extracted and tabulated. Data were inductively grouped into categories describing "modifiers" of adherence (verified by a second author) and systematically displayed with supporting illustrative quotes.

Results

Thirteen studies (14 study reports) were included; eight recruited only or predominantly women with urinary incontinence, three recruited postnatal women, and two included women with pelvic organ prolapse. The quality of methodological reporting varied. Six "modifiers" of adherence were described: knowledge; physical skill; feelings about PFMT; cognitive analysis, planning, and attention; prioritization; and service provision. 
Conclusions

Individuals' experience substantial difficulties with capability (particularly knowledge and skills), motivation (especially associated with the considerable cognitive demands of PFMT), and opportunity (as external factors generate competing priorities) when adopting and maintaining a PFMT program. Expert consensus was that judicious selection and deliberate application of appropriate behavior change strategies directed to the "modifiers" of adherence identified in the review may improve PFMT outcomes. Future research is needed to explore whether the review findings are congruent with the PFMT experiences of antenatal women, men, and adults with fecal incontinence.

\section{INTRODUCTION}

This article reviews the primary qualitative literature exploring patients' experiences of pelvic floor muscle training (PFMT). It is the third of four papers from the State-of-the-Science Seminar "Improving Pelvic Floor Muscle Training Adherence Strategies: from theory to practice," funded by the ICS, held in Glasgow prior to the 41st ICS Conference in 2011. The conference was instrumental in developing the "2014 Consensus Statement on PFMT Adherence."

PFMT can prevent and treat urinary and fecal incontinence in men and women and pelvic organ prolapse (POP) in women.[1] Three preconditions of effective PFMT are: (i) a correct pelvic floor muscle (PFM) contraction; (ii) sufficient exercise dose to achieve desired physiological muscle response (e.g., hypertrophy); and (iii) treatment adherence, to achieve the exercise dose. Adherence rates in PFMT trials vary; considerably.[2] Some variability reflects the difficulty in measuring adherence[3] and the different measures used.[2] Other influences on PFMT adherence include differences in supervision intensity (more contact supports adherence),[4] whether patients know adherence is being measured, and measurement timing (i.e., during, immediately after or well after supervised treatment).[2]

Based on Cochrane systematic reviews, [4-6] many PFMT trials include intervention components that might support adherence, such as the offer of information or education, teaching (e.g., a correct PFM contraction), reminders, supervision, and biofeedback. However, few trials reported that these components were specifically selected to promote adherence and even fewer investigated their effects as adherence strategies.[2]

Understanding patients' perspectives may help direct behavior change interventions toward cognitive, affective, social, and environmental influences on PFMT behavior; illuminate the thoughts, feelings, and circumstances that underpin quantitatively documented determinants of PFMT adherence; and suggest other influences not yet investigated. The aim of this article is to synthesize PFMT experiences described in qualitative studies and discuss the implications for clinical practice and future research. 
This article, in contrast to Paper II, uses the term "modifiers" rather than "determinant." We considered "determinant" was more appropriately reserved for moderating or mediating variables with quantitatively demonstrated adherence-predictive value[7]; "modifiers" better describes potential influences on adherence emerging from the inductive analysis of qualitative data reported here.

\section{MATERIALS AND METHODS}

Refer to the Materials and Method section of the 2014 Consensus Statement for details of the initial literature search. Thirty studies were screened; seven met the inclusion criteria. Two additional, eligible studies (discussed in three articles) were found in supplementary Medline, Cinahl, and Psyclnfo searches (database origin to August 2012) conducted by the first author using keywords ([qualitative OR phenomenolog\$ OR thematic OR theme\$].ab AND [pelvic adj3 [exercis\$' OR training].tw]).

No additional studies were found from reference-list checks. Four further studies were identified by panel experts (from the 2011 Seminar): one was published in a Taiwanese journal,[8] two were postgraduate theses $[9,10]$, one of which was subsequently published,[11] and a study presented as a conference abstract.[12]

Eligibility and Screening

Two reviewers independently screened all records without prior consideration of results; eligibility disagreements were resolved through discussion. Studies were included if:

- Published (full paper or abstract) in peer-reviewed literature or conference proceedings, or a thesis/dissertation submitted for a higher university degree.

- A recognizable method was used for qualitative data collection (e.g., interview), although interviewer-led structured surveys were ineligible.

- Findings were supported by "raw" data (i.e., verbatim participant quotes). Data were the experiences of women or men regarding PFMT (with or without other interventions) to prevent or treat urinary or fecal (including flatus) incontinence or POP. Studies that focused on experiences of incontinence or POP were only eligible if raw data were included on PFMT experiences.

- Data from patients with incontinence or prolapse were not merged with data from patients with other conditions (e.g., sexual dysfunction, chronic pelvic pain) or other sources (e.g., caregivers, health professionals).

- Published in English or French.

Data Extraction, Description, and Assessment of Methodological Quality

Details of participants, study aims, methodology, data collection methods, and analysis were extracted (verbatim) and tabulated by one reviewer, and cross-checked by a second. Methodological quality critique was limited to three credibility elements[13]: (i) description of 
the step-by-step thematic analysis process, (ii) use of multiple or independent persons and/or study participants to verify the analysis, and (iii) inclusion of verbatim quotes to substantiate the themes. Credibility ratings of high, moderate, and low were assigned; high-credibility studies detailed all three components and any weakness in study design/conduct were thought unlikely to affect credibility of findings; low-credibility studies only satisfied the criterion for inclusion of quotes (weaknesses likely to affect credibility); and the remainder were classified as moderate credibility (weaknesses may affect credibility). The rating did not include other elements of trustworthiness (e.g., dependability, confirmability).[13]

Data Analysis

Each study's themes (with constituent verbatim participant quotes and study authors' accompanying explanations) were extracted to a data matrix. One reviewer (verified by a second) undertook a conventional inductive content analysis,[14] grouping data into higher order themes representing possible PFMT adherence modifiers. Each modifier was described, studies contributing data listed, representative quotes selected, and tabulated. The findings were circulated to and agreed by the expert panel from the 2011 Seminar.

\section{RESULTS}

Thirteen studies (in 14 study reports) $[15,16]$ were included (Table I). Seven recruited only women, [8, 12, 17-21] and another predominantly women (five men and 38 women)[22] with urinary incontinence (UI). Three recruited postnatal women, $[15,16,23,24]$ and two recruited women with POP.[9, 10] Five studies included older women (>65 years) $[9,10,18,20,22]$; one[12] specifically recruited older women. Five studies recruited or included non-Caucasian ethnicities, $[8,10,15,16,19,21]$ and six reported demographics, suggesting participation from a range of socioeconomic backgrounds.[8, 17, 19-22] 
Table I. Description of Studies and Participants

\begin{tabular}{|c|c|c|c|}
\hline Study & Participants & $\begin{array}{l}\text { Study aim and } \\
\text { methodology }\end{array}$ & $\begin{array}{l}\text { Data collection and } \\
\text { analysis }\end{array}$ \\
\hline \multicolumn{4}{|c|}{$\begin{array}{l}\text { PFMT: pelvic floor muscle training, } \\
\text { incontinence. }\end{array}$} \\
\hline \multicolumn{4}{|c|}{ 1. PFMT for urinary incontinence (UI) } \\
\hline \multirow[t]{4}{*}{$\begin{array}{l}\text { Ashworth } \\
\text { and } \\
\text { Hagan[17] }\end{array}$} & $\begin{array}{l}\text { Sample: } 28 \text { women with } \\
\text { UI symptoms. }\end{array}$ & $\begin{array}{l}\text { Aim: To describe how } \\
\text { women understood the } \\
\text { social and emotional } \\
\text { consequences of non- } \\
\text { compliance with PFMT. }\end{array}$ & $\begin{array}{l}\text { Data collection: Face to face } \\
\text { interviews with one of two } \\
\text { experienced female interviewers } \\
\text { in the participant's own home. } \\
\text { Interview duration of } 20 \mathrm{~min} \text { to } \\
2 \mathrm{hr} \text {. }\end{array}$ \\
\hline & Age: $25-55$ years. & $\begin{array}{l}\text { Methodological framework: } \\
\text { Phenomenological }\end{array}$ & $\begin{array}{l}\text { Data analysis: Identification and } \\
\text { then grouping of "meaning units" } \\
\text { to form themes. First } 15 \\
\text { interviews in detail and remaining } \\
13 \text { used to corroborate and } \\
\text { challenge analysis. }\end{array}$ \\
\hline & $\begin{array}{l}\text { Social class: } 8 \mathrm{~B}, 5 \mathrm{C} 1 \text {, } \\
15 \mathrm{C} 2 \text {. }\end{array}$ & & \\
\hline & $\begin{array}{l}\text { Setting: Recruited from } \\
\text { newspaper } \\
\text { advertisements, UK. }\end{array}$ & & \\
\hline \multirow[t]{2}{*}{ Chen et al.[8] } & $\begin{array}{l}\text { Sample: Eight married } \\
\text { parous women } \quad \text { with } \\
\text { genuine } \\
\text { incontinence (six women) } \\
\text { or mixed UI (two women) } \\
\text { symptoms. }\end{array}$ & $\begin{array}{l}\text { Aim: Get feedback on } \\
\text { experiences of PFMT. }\end{array}$ & $\begin{array}{l}\text { Data collection: Audiotaped } \\
\text { interviews at a venue of the } \\
\text { participant's choosing. Interview } \\
\text { duration of } 60-90 \mathrm{~min} \text {. }\end{array}$ \\
\hline & Age: $30-64$ years. & $\begin{array}{l}\text { Methodological framework: } \\
\text { Not clearly stated. } \\
\text { Naturalistic enquiry? }\end{array}$ & $\begin{array}{l}\text { Data analysis: Verbatim } \\
\text { transcription and content analysis } \\
\text { with themes formulated from the } \\
\text { "significant" parts of participant } \\
\text { accounts. Co-researchers, not } \\
\text { involved with the interviews, read } \\
\text { the transcripts and helped refine }\end{array}$ \\
\hline
\end{tabular}


the themes.

Education: 6-14 years of schooling.

Setting: Recruited from sample of 55 women participating in a study investigating a theoretical model for predicting PFMT adherence, Taiwan.

Martin and Dumoulin (2012)

Hay-Smith et al.[18]
Sample: 27 communitydwelling women with stress or stresspredominant mixed UI.

Age: 60 years or older.

Setting: recruited from continence clinics of three major hospitals to participate in the pre-test post-test cohort study investigating the feasibility of PFMT classes for older women, Canada.

Sample: 20 women with stress UI or stresspredominant mixed UI.

Age: 35-85 years.
Aim: To investigate the feasibility of PFMT classes and to identify barriers and facilitators for class participation and daily home PFMT.

Methodological framework: A cross-sectional qualitative study using focus group methodology.

Aim: To explore women's experiences of PFMT to provide insights into interpreting the trial findings.

Methodological framework: Qualitative description.
Data collection: Four moderated focus groups of six to eight women after a 12-week PFMT class program. Data were collected, revised, and compiled using a tape-based abridged transcript method.

Data analysis: A long-table approach and data were organised according to facilitator and barrier identification and level of importance.
Data collection: Face-to-face interviews with single interviewer (the trial physiotherapist) at venue of participant's choice. Interview duration of 30-90 $\mathrm{min}$.

Data analysis: Identification, coding, and grouping of meaning units into themes. Analysis began before all interviews were complete, and the developing analysis was checked in later 
Setting: 10 women from each arm of a two-arm RCT comparing approaches to PFMT, New Zealand.

Kincade et Sample: 10 women who al.[20]

MacInnes[21]

Deprivation category: 3 to 7 (where 7 is most minimum.

interviews. Validity check of themes from an independent researcher.

Sample: 12 women who dropped out of stress UI treatment (missed >2 appointments).

Age: $28-65$ years.

Aim: To find out why patients did not complete treatment so strategies could be developed to improve adherence.

Methodological framework: Not stated.

Education: Seven with college education as

Setting: A communitybased continence clinic ding interdisciplinary, comprehensive

behavioral, and pharmacological management of UI, USA.
Data collection: Face-to-face interviews conducted by a single female interviewer not involved in care.

Data analysis: No details given. Not clearly stated.

Aim: To find out why patients did not complete treatment so strategies could be developed to improve adherence.

Methodological framework:

Data analysis: Themes identified and put in tables to enable examination and comparison.
Data collection: Telephone interviews with a single researcher. Interview duration was approximately $40 \mathrm{~min}$. 
deprived).

Ethnicity: 11 British, one British-Asian.

Setting: Nurse-led continence clinic, UK.

Milne and Moore[22]

community-dwelling, and
independent in activities
of daily living.

Age: $24-86$ years.

Education: $58 \%$ college education as minimum.

Setting: Recruited from public advertisement and word of mouth[14] and continence clinics,[24] Canada.

van den Muijsenberg \& LagroJanssen[19]
Aim: To gain understanding of self-management strategies and the facilitators and barriers for maintenance of behavioral therapies

Methodological framework: Qualitative description, guided by the Health Promotion Model.

Aim: To explore perceptions of incontinence and its treatment.
Data collection: 25 semistructured face-to-face interviews in participants' home and three focus groups of three, three, and seven individuals, moderated by the researcher. Interviews were recorded and detailed notes taken (by an observer with focus group experience) in the focus groups. Interview duration was approximately $60 \mathrm{~min}$ and focus groups approximately $2 \mathrm{hr}$,

Data analysis: Preliminary broad coding of meaning units within their context, then within code analysis of commonality and divergence to form sub-codes. Codes reviewed with another person. Final analysis looked for unifying links within and between categories.
Data collection: Face-to-face semi-structured in depth interviews with Muslim female researcher held at patients' home or doctors' surgery. Sometimes a female family member (eight cases) or translator (eight cases) was present for translation. 
Interview duration of 45-60 min.

Age: $25-65$ years.

Education: 2 none, 14 low, 5 intermediate, 5 high.

Ethnicity: 13 Moroccan, 17 Turkish.

Setting: Participants recruited from six general practices in four cities: one physiotherapy practice, two female Moroccan consultants, the Netherlands.

2. PFMT for pelvic organ prolapse (POP)

Hyland[10] Sample: Five women with POP.

Age: $>40$ and $<70$ years.

Ethnicity: Three Caucasian, oneNew Zealand Maori, one Asian.

Setting: All five women participated in the PFMT arm of a large multicenter
Methodological framework: Not stated.

Aim: To understand the experiences of long-term PFMT for POP.

Methodological framework: Interpretative phenomenological analysis.
Data analysis: Independent thematic analysis by two researchers.
Data collection: Face-to-face interviews with single interviewer (the trial physiotherapist) at a venue of participants' choice. Interview duration of 40-60 min.

Data analysis: Thematic analysis of each transcript, then across the interviews by grouping data. Verification of themes with thesis supervisors, and member checking using a summary of themes from each individual's transcript. 
RCT examining the effects of PFMT and lifestyle advice on POP, New Zealand.

Mahfooza[9] Sample: 15 women with POP.

Age: 40-79 years.

Setting: Eight from the PFMT group and seven from lifestyle advice group in a large multicenter RCT examining the effects of PFMT and lifestyle advice on POP, Australia.

3. Postnatal PFMT

Chiarelli and Cockburn[24]
Sample: 37 postnatal women.

Age: 23-38 years.

Parity: 34 primiparous.

Setting: Attendees at early childhood centers in a single city, Australia
Aim: To explore experience of POP, trial participation, and influences on adherence to the research protocol.

Methodological framework: Thematic analysis, informed by grounded theory.

Aim: To use information from women to develop an acceptable and effective continence promotion program.

Methodological framework: Not clearly stated. Guided by the theories of health promotion and the Health Belief Model.
Data collection: Two researchers conducted 4 face-to-face semistructured interviews in a consultation room at a hospital or in the woman's home, and 11 telephone interviews. Interview duration was of 15-40 min.

Data analysis: Line-by-line coding and constant comparison of the identified codes and categories, within and between the two groups of participants, to develop major categories or themes.

Data collection: Four focus groups, using "funnelling" questions.

Data analysis: Responses grouped according to the nine aims of study, with 10th group for responses not fitting nominated categories. 
Gillard and Shamley[23]

Sample: 10 postnatal women with second, third, or fourth degree perineal tear.

Parity: Five primiparous.

Setting: Single center, UK.

Mason et
al. $[15,16]$

Sample: 42 postnatal women with stress UI symptoms 8 weeks postnatally.

Age: $21-45$ years.

Parity: 1-7.

Setting: 42 women selected from 179 survey responses, two hospitals, UK.
Aim: To identify motivators of PFMT following a perineal tear at delivery

Methodological framework: Hermeneutic interpretative phenomenology, guided by the Health Belief Model.

Aim: To find out whether women follow routine PFMT instruction given during pregnancy or after delivery; why or why not.

Methodological framework: Not stated. Presumed descriptive qualitative.
Data collection: Face-to-face interviews with single interviewer in participants' own home.

Data analysis: Data grouped under the 18 questions, then combined under the Health Belief Model headings. Thematic analysis informed by hermeneutics.

Data collection: Face-to-face interviews with a single female interviewer in the participants'home. Some interviews were audio-recorded and some not (shorthand notes taken). Interview duration 20$90 \mathrm{~min}$.

Data analysis: Coding until no new meaning units found. Analysis considered specific a priori questions and ideas, phenomena emerging from the data, and contradictions and repetitions with the data. Counts of themes across transcripts to indicate importance.

\footnotetext{
Patient perceptions of PFMT were explored in the context of postnatal continence promotion, [24] UI self-care,[22] UI experiences, including treatment[17, 19], experiences of POP and PFMT trial participation,[9] the feasibility of PFMT classes, including participation barriers and facilitators,[12] PFMT experiences,[8, 10, 15, 16, 18, 23] and non-completion of UI treatment.[20, 21]
} 
The methodological quality varied. Based on reporting, three were of low, [12, 20, 24] five moderate, $[9,15-17,21,23]$ and four high credibility.[10, 18, 19, 22] Three studies stated their theoretical position was phenomenological, $[10,17,23]$ whereas the remainder were described as or appeared to fit the criteria for qualitative description.[25] All studies analyzed data using some variant of thematic analysis.[26] Two studies[23, 24] chose, a priori, the Health Belief Model[27] to direct the analysis.

Table II presents the six higher order categories (potential adherence modifiers) inductively derived from content analysis of primary study data. Each modifier was supported by data from multiple studies, and every category contained data from one or more high credibility study. The six modifiers were "knowledge", "physical skill", "feelings about PFMT", "cognitive analysis, planning, and attention", "prioritization", and "service provision". All 13 studies contributed data to two modifiers "cognitive analysis, planning, and attention" and "prioritization", and 12 (including the four high-credibility studies) contributed data to "knowledge".

Table II. 'Modifiers' of Adherence

\section{Description}

Representative quotes (with source) and contributing studiesa

aBold typeface denotes studies with high credibility rating

PFM: pelvic floor muscle; PFME: PFM exercises; PFMT: PFM training; PFX: pelvic floor exercises; POP: pelvic organ prolapse.

\section{Knowledge}

A range of PFMT information sources were identified (e.g., hospital leaflets, television, internet, and print media). The pre/post-natal period was a common time to be offered PFMT information from a health professional (a credible source), although information delivery and sufficiency were much criticized. Those who sought help because of symptoms, appeared more positive about information content and delivery, although vaginal examination (while ultimately useful to women) could be considered intrusive and difficult to cope with at the time. When information made sense to women, it became valuable and actionable knowledge. "Personal" stories and contact appeared to facilitate knowledge acquisition.

\section{Sources, sufficiency, and delivery of information}

"I was left a stack of leaflets straight after the birth. Anonymous leaflets, down to me to sort the information out. It was just put at the end of the bed, nothing was said. It wasn't satisfactory. It would be helpful if somebody went through the leaflets, it's like junk mail-just given a stack of mail, very easy to dump them". (Mason et al.,[16] p. 59)

"oh yes the internals uh and the externals and the whole. Gee, I felt what have I put myself in for, I thought I'll just pull out now. But being really conscious of the fact that with aging and problems of developing and being told by a couple of health 

contributing studies $a$

professional people that I've got some type of a prolapse, I thought I should persevere". (Mahfooza,[9] p. 99)

\section{Actionable knowledge (or lack of)}

"I thought, do I have to do sport here? Ridiculous! Will it help? How am I supposed to contract and relax my pelvic floor muscles?" (van den Muijsenberg and Lagro-Janssen,[19] p. 947)

"The physio, apart from saying what's what, we did them in class. She said you can feel the muscles contracting if you got to the loos and stop. She also gave out leaflets as well. She had diagrams she'd photocopied from the manual or book. Explained what was what, how to do them and how often. She got us to do some there and then and asked if we could feel the muscle, tried to explain what muscle it was ... She made sure your partner can feel it". (Mason et al.,[16] p. 59)

Contributing studies: Ashworth and Hagan[17]; Chiarelli and Cockburn[24]; Gillard and Shamley[23]; Hay-Smith et al.[18]; Hyland10; Kincade et al.[20]; Mahfooza[9]; Martin and Dumoulin (2012); Mason et al[15, 16]; Milne and Moore[22]; van den Muijsenberg and LagroJanssen 19 .

\section{Physical skill}

Performing PFMT required a "bodily" knowledge of PFMs that was not easy to achieve. Physical mastery of a correct contraction (assisted in some cases by observation via biofeedback) reinforced belief in one's skills and fostered selfefficacy. Mastery of other exercises did not translate to mastery of a PFM contraction.

\section{Bodily knowledge and mastering a contraction}

"We're trying to do it [PFME] after a couple of kids, and we don't even know where those muscles are anymore. It's hard to visualize or feel those muscles when you haven't used them for years". (Milne and Moore,[22] p. 47).

"I feel that the qi [inner energy] gathers around the flank area, and then I would feel whether I contract 

contributing studies $a$

there [pelvic floor muscle] or not. I always feel that I do it incorrectly. I can feel it while contracting but I cannot feel it while relaxing. Every time, when I relax, I have to feel whether I am relaxed or not, every time. I keep doubting if I'm doing it correctly" (Chen et al.,[8] p. 17)

\section{Contraction self-efficacy}

"[Referring to biofeedback with pelvic muscle exercises.] Well, I could see on the chart if I was doing it well depending on how high the marker went on the chart. I knew I could control it when I watched that, you see, and know what I was doing. And, of course, I was helped along with that. She [the nurse] was talking to me the whole time". (Kincade et al.,[20] p. 387)

"When I do cough, or involuntarily sneeze, it doesn't leak, but then I'm conscious that I'm actually pulling pelvic floor and tummy muscles in and I can control the leakage, well I can actually stop it". (Hay-Smith et al.,[18] p. 56)

Contributing studies: Ashworth and Hagan[17]; Chiarelli and Cockburn[24]; Chen et al.[8]; Gillard and Shamley[23]; Hay-Smith et al.[18]; Hyland[10]; Kincade et al.[20]; Mahfooza[9]; Martin and Dumoulin (2012); Mason et al.[16]; Milne and Moore[22].

\section{Feelings about PFMT}

Some individuals had a positive emotional response to PFMT. More commonly, feelings (emotive and bodily sensations) were couched in the negative. PFMT did not necessarily confer feelings of innate reward, and it was common to characterize oneself as lacking motivation for PFMT. The dissonance arising from feeling that one should exercise and that one lacked motivation was perceived as a personal weakness or fault leading to self-blame. In addition, it was assumed that others

\section{Cognitive or bodily responses to PFMT}

"[learning pelvic floor exercises] was quite uplifting. It made me feel, it is a feeling of sort of energising, you can master this yourself, you can take control of it ... she [physiotherapist] show me how much improved I can be and how I can do it". 


\section{Description}

(including health professionals) similarly attributed blame for failure to exercise.
Representative quotes (with source) and contributing studies

(Mahfooza,[9] p. 102)

"I can't really do them and they make me feel a wee bit sick". (MacInnes,[21] p. 51)"

\section{Self-blame}

"It's probably that we don't do [PFMT after childbirth] what we're supposed to do afterwards ... So it's my fault isn't it”. (Hay-Smith et al.,[18] p. 55)

"But I believe that it's a case of having to knuckle down to do them all the time and remember to do them all the time. I just haven't go that type of ... I'm not the type of person, with that willpower, I'm afraid to say". (Ashworth and Hagan[17], p. 469)

Contributing studies: Ashworth and Hagan[17]; Gillard and Shamley[23];Hay-Smith et al.[18]; Hyland[18]; Kincade et al.[20]; MacInnes[21]; Mahfooza[9]; Mason et al.[15].

\section{Analysis of worth \\ Analysis of worth}

PT was preceded by an analysis of the worth of exercise to self and others, now or in the future. Symptoms (threat, presence, or return of) were not necessarily sufficient reason to exercise and depended on beliefs about exercise efficacy and whether the effort was worth the outcome. The known or assumed views or experiences of others were influential in deciding on the worth of exercises. Once exercise commenced, the analysis of exercise value continued as outcomes were evaluated according to implicit or explicit expectations. Implementing and maintaining PFMT required conscious planning and problem solving; the biggest issues were identifying and organizing time, making exercise habitual, and coping with disruption. Sustained cognitive attention was needed to remember to exercise; external cues and accountability to a health professional or self during supervised treatment appeared to support remembering. Over time, cognitive attention to PFMT tended to become more intermittent and declined overall.
"I am paranoid about doing the exercises. It is an obsession ... to stop incontinence" (Gillard and Shamley,[23] p. 11)

"My mother ended her life incontinent; I don't want this to happen to me; this motivated me". (Martin and Dumoulin 2012)

"I started doing them initially because people said to do them. Because I kept getting the same information from lots of different sources". (Mason,[15] p. 665) 

contributing studiesa

"I was given pelvic floor exercises, and I had tried them before. I used to go to the physio ... and they never worked then, so I don't think they would work now". (MacInnes,[21] p. 52)

\section{Conscious planning}

"It is a different thing about remembering to do them and getting time to do them". (Gillard and Shamley,[23] p. 11)

"It's never a problem, 'cause most times of the day you can do them. Nobody knows you're doing them, so it's just one of those things you can stand and talk to someone a do a few". (Hay-Smith et al.,[18] p. 57)

Milne and Moore[22] (p. 47) stated "the majority of individuals who had maintained their PFME were doing their exercises once daily, usually in the morning before going out. One concluded, "If I don't, well then, it [the time needed] is usually gone".

\section{Sustained cognitive attention}

"I've always led a busy life and the things that don't give you a reason to be on top of them, you forget". (Milne and Moore,[22] p. 47)

"Someone should put up a billboard somewhere saying HAVE YOU DONE YOURS TODAY?women would know what they were on about but no-one else would know". (Chiarelli and Cockburn,[24] p. 116)

Contributing studies: Ashworth and Hagan[17]; Chiarelli and Cockburn[24]; Chen et al.[8]; Gillard and Shamley[23]; Hay-Smith et al.[18]; Hyland[10]; Kincade et al.[20]; MacInnes[21]; Mahfooza[9]; Martin and Dumoulin (2012); Mason et al.[15]; Milne and 
Description

\section{Prioritization}

The demands of doing PFMT were weighed against the availability of personal resources (e.g., time, energy), in the context of competing priorities. Competing priorities were intrapersonal (e.g., one's own health concerns), inter-personal (e.g., family roles and responsibilities), and other social roles (e.g., work). Giving priority to PFMT was supported by a belief in, hope for, or observation of, a desirable exercise outcome. Compromise was commonplace, resulting in partial adherence (i.e., continuing to exercise at less than the recommended dose), and choices about priority for PFMT were made at a given moment (i.e., what is most important right now) and over time (i.e., what is more important in the mid term to long term).
Representative quotes (with source) and contributing studiesa

\author{
Moore[22]; van den Muijsenberg and Lagro- \\ Janssen[19].
}

PFMT demands versus available resource

"The baby was so active that you don't get five minutes for yourself". (Mason,[15] p. 666)

"I work at a restaurant, so when a customer comes in, I have to stop focusing [on doing PFM exercise]. So, it is interrupted. Usually I hurry to get ready for work as soon as I wake up, or have no free time due to working two shifts a day when a colleague sometimes leaves" (Chen et al.,[8] p. 17)

\section{Deciding PFMT priorities}

"I did [PFMT] initially but since the program has finished ... I needed to lose weight more than I need to worry about my prolapse because my back was so bad. So I hadn't really - didn't have much of a choice". (Mahfooza,[9] p. 106)

"I can think about it once every blue moon and think "Oh yes I ought to do those". But while I'm doing something else I think "Oh forget about it". (Ashworth and Hagan,[17] p. 468)

"Here was something I could do, I could take charge of,... I used to take exercise classes and do pelvic floor exercises with groups, I knew it in my head, but I didn't do it for me. So this is for me, this is something I can do, and if I do it well, I'll retain the long-term benefits". (Hay-Smith et al.,[18] p. 57)

Contributing studies: Ashworth and Hagan[17]; Chiarelli and Cockburn[24]; Chen et al.[8]; HaySmith et al.[18];Hyland[10]; Kincade et al.[20]; MacInnes[21]; Mahfooza[9]; Martin and Dumoulin 
Description

\section{Service provision}

The provider's cost and location, and how appointments were (re) arranged, influenced attendance for PFMT teaching and supervision.
Representative quotes (with source) and contributing studies

(2012); Mason et al.[15, 16]; Milne and Moore[22]; van den Muijsenberg and LagroJanssen (2003).

"It's motivating to work in a group". (Martin and Dumoulin 2012)

MacInnes[21] (p52) stated that "reasons for dropping out of therapy" included "forgotten/mixed up appointments" and "no evening clinics available".

"it takes a bit of your time that's the only thing that .. wasn't good and the fact that I have to travel to go the appointments so I wasn't happy about that when I have [hospital] right near me and I couldn't go there, I had to travel to [trial site] which-that was you know a pain in the bum".[9] (p. 112)

Contributing studies: Kincade et al.[20]; MacInnes[21]; Mahfooza[9]; Martin and Dumoulin (2012); Milne and Moore[22].

The six modifiers are linked and interactive: we saw that one may alter the effect of another and potential for some modifiers to have greater influence on certain individuals or in particular contexts. Our analysis did not intend to develop a theory of PFMT adherence. Thus, we limit ourselves to a few examples below of the possible inter-relationships between modifiers. Knowledge and cognitive analysis may interact; those with incomplete, confused, or inaccurate information about PFM disorders and the preventive/treatment effects of PFMT, lack useful knowledge to assess exercise worth. Physical skill and emotional response may be connected; individuals who master a contraction and achieve contraction self-efficacy may experience the sense of empowerment and control with PFMT. Cognitive analysis and planning are inherently linked with prioritization. Persons who experience competing demands on their time and energy resources may need more support to scrutinize their daily lives and develop plans to cope with disruptions and conflicting priorities. Further, deciding priorities is allied to decisions about 
PFMT value. Those who encounter difficulties with service provision (e.g., travel distance/time) will likely include this in their assessment of PFMT demand versus available resources.

\section{DISCUSSION}

Our review of primary qualitative studies elucidates the nature of cognitive, physical, and affective experiences on which PFMT behavior and adherence are founded. The findings suggest multiple, interacting PFMT adherence modifiers. We found congruence between our findings and existing measures of PFMT self-efficacy and treatment motivation, as well as with broader theories of health behavior and adherence.[27]

Comparing individual response items from the three measures of PFMT self-efficacy[28-30] and the Incontinence Treatment Motivation Questionnaire[31] to the six modifiers, we could map each item to one or more of the modifier categories. Response items in these instruments often included multiple modifiers. In particular, "physical skill" and "cognitive analysis, planning, and attention" were commonly combined to cover specific components of, or contexts for, PFMT behavior (e.g., I believe I can contract my PFM for a duration of $5 \mathrm{sec}$.[30] How confident are you that you can contract your muscles when lifting a bag of groceries?[28]). However, the modifiers "feelings about PFMT' and "prioritization" were not well represented in the instruments, and 'service provision' was not included at all.

A plethora of models explicate the intricacies of health behavior and adherence.[27] Postanalysis, we mapped the six modifiers to one overarching framework of health behavior, the Capability, Opportunity, and Motivation Behavior (COM-B) system,[32] to identify appropriate targets for enhancing adherence in practice and for testing in future research.

As briefly introduced in paper 1 , the COM-B is a "systems approach to understanding behavior in context" (p. 233). In addition to being a framework for understanding behavior, it offers a starting point for the design of behavior change interventions. The COM-B explains behavior as the outcome of three interacting factors: capability (knowledge and skills necessary to participate in the endeavor), opportunity (context external to the person that facilitates or impedes the behavior), and motivation (an individual's conscious, habitual, affective, and automatic processes that animate and direct the behavior). In turn, performance of the desired behavior impacts capability, opportunity, and motivation.[32]

Two modifiers, "knowledge" and "physical skill", contribute to capability. Problems with the sufficiency and delivery of information meant that individuals remained confused or unconvinced about PFMT; hence, exercises were not adopted. Conversely, information that made sense provided a basis for further action. "Physical skill" describes the development of the physical capability for PFMT, which included bodily knowledge and mastery of a voluntary PFM contraction. Congruent with the COM-B feedback loop, developing mastery of a PFM contraction supported positive beliefs about performance and fostered contraction self-efficacy and helped motivate more PFMT. 
The conscious and unconscious motivations of the COM-B were represented by three modifiers: "feelings about PFMT", "cognitive analysis, planning, and attention", and "prioritization". Exercises engendered positivity for some, whereas others described less positive affective responses (e.g., discomfort, frustration, intrusion, lack of salience). For the former, training was reinforced by feelings of self-control, whereas, for the latter, a failure to exercise often resulted in self-blame. The most substantive modifier (in terms of how much the primary studies mentioned it) was the amount of cognitive activity required for PFMT adherence. Study participants described evaluating whether the exercises were worth it, thinking about how daily habits could be changed to include PFMT, problem solving to deal with disruptions, and ways to keep PFMT in their consciousness over many days and months. PFMT prioritization and the decision to exercise (not exercise or partially adhere) were influenced by internal resources (e.g., perceptions of time and energy), as well as external issues.

The influence of factors outside the individual (called opportunity in the COM-B) on motivation and behavior was portrayed in several modifiers. For example, the stories and opinions of others were persuasive. The expectation of censure from others for failure to exercise potentially led to feelings of self-blame, and the views of credible others were incorporated in the analysis of PFMT worth. Further, much of the disruption experienced by individuals, the competition for resources and subsequent decisions about PFMT priority, were centered on external factors (particularly family and work). Finally, the modifier we titled "service provision" described external influences (e.g., timing and location) on PFMT motivation and behavior.

Michie et al. describe a behavior change wheel, with the COM-B at the center and two further circular layers.[32] The first circular layer outside the COMB-B shows nine intervention functions that support behavior change: education, persuasion, incentivization, coercion, training, enablement, modeling, environmental restructuring, and restrictions. To consider the implications of the review findings for designing PFMT interventions to support behavior change and adherence, each of the nine intervention functions is briefly discussed.

Four of the nine intervention functions, when mapped to our six modifiers, clearly had potential to support behavior change: (i) the content and delivery of education to impart knowledge and develop understanding, (ii) training skills for correct and improved PFM contraction performance, (iii) the clinician's ability to persuade and induce, through skillful communication, consistent PFMT behavior and positive feelings about PFMT (while decreasing negative feelings, such as self-blame), and (iv) enabling PFMT through maximizing available patient and clinician resources (e.g., provision and uptake of treatment supervision) and minimizing barriers.

Two of the nine intervention functions (modeling, environmental restructuring) mapped less well. Modeling appeared only in the "negative" (e.g., not wanting to be like someone known to be incontinent because of odor or some other clue, or giving credence to another person's doubts about PFMT efficacy). Thus, providing images or "stories" of a person or situation to which the individual aspires or other strategies to provide positive modeling are a potential area for development in clinical practice and research. Attention is also needed to address issues 
encompassed by environmental restructuring (e.g., the limited attention and priority given to PFM health in the context of care for pregnant and postpartum women[2]). Neither the review nor the expert consensus identified a clear role for the three remaining intervention functionscoercion, incentivization, and restriction - in promoting PFMT adherence.

Based on the review of PFMT experiences within the context of the COM-B and behavior change wheel,[32] we recommend the following to clinicians.

As educator, provide information in a way that facilitates understanding about what to do and why. In particular, it is important that patients understand that PFMT is essentially a selfmanagement program and results are dependent on their active participation. As many patients think of treatment in terms of taking medication and being cured, it is also essential that they understand PFMT relies on lifetime rather than short-term behavior change.

As trainer, identify correct and incorrect PFM activities, provide feedback on PFM contractions, reinforce correct performance, promote contraction self-efficacy, and individualize treatment protocols.

As persuader, encourage patients, nurture positive thoughts and feelings about PFMT, avoid imparting guilt or blame for past or current failures of exercise adherence, and help patients identify reasons why exercise is of personal worth and priority. It is generally accepted that clinicians should understand their patients' expectations and promote realistic expectations of treatment and outcome. From a behavioral perspective, this is important because expectations affect motivation and adherence, as well as perceptions of outcomes as successes or failures. Unrealistic expectations quickly lead to discouragement. Realistic expectations enable patients to buffer failure experiences and persist in the face of setbacks.

As enabler, support problem-solving to help patients anticipate potential adherence barriers (such as forgetting and disruptions), identify and monitor barriers as they are experienced, and foster active planning to find solutions. Also, provide supervision and accountability for exercising in the short-term and encourage a problem-solving approach to maintaining cognitive attention to PFMT over time. Follow-up to assess adherence, monitor progress, and encourage persistence-is thought to facilitate long-term behavior change.

While espousing these four functions (educator, trainer, persuader, and enabler), we opine that their effect is greatest in the context of a therapeutic relationship characterized by trust and credibility. A good working alliance is a sound foundation for facilitating adherence.[34]

The review findings are limited to PFMT experiences in postnatal, midlife, or older women with UI or POP. None of the included studies recruited only or predominantly men, antenatal women, or participants with fecal incontinence. Future research could address the absence of reported PFMT experiences in these groups to investigate congruence with and extend understanding of 
our findings. Further research is also needed to investigate the predictive value of the PFMT adherence modifiers and whether the recommended interventions increase PFMT adherence to moderate or mediate incontinence and prolapse outcomes.

\section{CONCLUSION}

The six PFMT adherence modifiers derived from our synthesis of data from 13 qualitative studies mapped well to an overarching framework of health behavior, the COM-B system. Postnatal, midlife, and older women experienced difficulties with PFMT capability (knowledge and skills), motivation (especially, the substantive cognitive demand of the exercises and negative feelings about and problems prioritising PFMT), and opportunity (external factors, such as competition for personal resources, the views of others, and service provision). Expert consensus was that the use of appropriate behavior-change techniques directed at the identified modifiers of PFMT adherence may improve outcomes. More research is needed to address the gap in understanding around PFMT experiences of antenatal women, men, and people with fecal incontinence.

\section{Clinical Recommendations:}

- At all levels (guidelines, patient/clinician), adopt an approach to the design and implementation of PFMT interventions (prevention and treatment) that incorporates appropriate behavior change techniques to promote exercise adherence. Specifically:

- Develop accurate and sufficient patient "knowledge" through judicious selection of content and delivery of information.

- Teach skills, then enhance performance in the correct "physical skill" of a PFM contraction and develop patient confidence in correct performance.

- Promote positive and decrease negative "feelings about PFMT" and counter negative with positive role models for PFMT.

- Enable constructive "cognitive analysis, planning, and attention" to problem-solve common PFMT barriers, and enhance PFMT facilitators, in daily life.

- Boost the "prioritization" of PFMT in patients' lives.

\section{Research Recommendations:}

- Address the absence of primary qualitative research exploring PFMT experiences in men, antenatal women, and those with fecal incontinence to investigate congruence with and extend understanding of these findings.

- Examine the predictive value of the six identified modifiers for PFMT adherence.

- Directly compare the effects of an intervention based on our recommendations (both intervention targets and use of behavior change strategies) versus "usual care."

- Investigate whether PFMT adherence mediates incontinence and prolapse outcomes. 
Disclosures as per ICS Disclosure Document

Jean Hay Smith: No disclosures.

Sarah Dean: No disclosures.

Kathryn Burgio: No disclosures.

Helena Frawley: No disclosures.

Chantale Dumoulin: No disclosures.

\section{Doreen McClurg: No disclosures.}

\section{ACKNOWLEDGEMENTS}

The authors wish to thank Gail Hyland, Aishath Mahfooza, and Clare Delany who provided thesis data for the paper; Diane Alewinjse who commented on the draft; and the 2011 expert panel who contributed to discussions: Ted Arnold, Kari B $\varnothing$, Pauline Chiarelli, Shu-Yueh Chen, Suzanne Hagen, Julia Herbert, Aishath Mahfooza, Frances Mair, Diane Stark, and Marijke van Kampen. Sarah Dean's time was partially supported by the National Institute for Health Research (NIHR) Collaboration for Leadership in Applied Health Research and Care (CLAHRC) for the South West Peninsula. The views expressed in this publication are those of the authors and not necessarily those of the NHS, the NIHR, or the Department of Health in England.

\section{REFERENCES}

1. Moore K, Dumoulin C, Bradley C, et al. Adult conservative management. In: Abrams PH, Cardoza L, Khoury AE, et al., editors. International Consultation on Urinary Incontinence. 5th edition. Plymbridge United Kingdom: Health Publication Ltd; 2013. 1112-1229.

2. Dumoulin C, Alewijnse D, Bo K, et al. Pelvic-floor-muscle training adherence: Tools, measurements and strategies-2011 ICS State-of-the-Science Seminar Research Paper II of IV. Submitted to Neurourol \& Urodynamics, 2014.

3. Vitolins MZ, Rand CS, Rapp SR, et al. Measuring adherence to behavioral and medical interventions. Controlled Clinical Trials 2000; 21:88S-194S.

4. Hay-Smith EJC, Herderschee R, Dumoulin C, et al. Comparisons of approaches to pelvic floor muscle training for urinary incontinence in women. Cochrane Database Syst Rev 2011;CD009508. doi:10.1002/14651858.CD009508.

5. Herderschee R, Hay-Smith EJC, Herbison GP, et al. Feedback or biofeedback to augment pelvic floor muscle training for urinary incontinence in women. Cochrane Database Syst Rev 2011;CD009252. doi:10.1002/14651858.CD009252. 
6. Dumoulin C, Hay-Smith J. Pelvic floor muscle training versus no treatment, or inactive control treatments, for urinary incontinence in women. Cochrane Database Syst Rev 2010; CD005654. doi:10.1002/14651858.CD005654.pub2.

7. Chen S-Y, Tzeng Y-L. Path analysis for adherence to pelvic floor muscle exercise among women with urinary incontinence. J Nurs Res 2009; 17:83-92.

8. Chen S-Y, Chien S-C, Huang L-G. Women's perceived barriers to performing a pelvic floor muscle exercise: A qualitative approach. Cheng Ching Med J 2008; 4:14-22.

9. Mahfooza A. Experiences in women with pelvic organ prolapse participating in a randomised controlled trial of physiotherapy treatment: A qualitative study. Melbourne: University of Melbourne 2011.

10. Hyland $G$ Women's experiences of doing long-term pelvic floor muscle exercises for the treatment of pelvic organ prolapse symptoms (MHealSc thesis). Wellington, New Zealand: University of Otago, Department of Medicine (UOW) 2012.

11. Hyland G, Hay-Smith J, Treharne G. Women's experiences of doing long-term pelvic floor muscle exercises for the treatment of pelvic organ prolapse symptoms. Int Urogynecol J 2013. doi:10.1007/s00192-013-2202-z.

12. Martin C, Dumoulin C. Factors that impact incontinent women's participation in pelvic floor muscle exercise classes and home programs. World Congress of Physical Therapy Abstract book, Vancouver, June 2007.

13. Letts L, Wilkins S, Law M, et al. Guidelines for critical review form: Qualitative studies (Version 2. 0). McMaster University 2007.

14. Hsieh H-F, Shannon SE. Three approaches to qualitative content analysis. Qual Health Res 2005; 15:1277-1288. doi:10.177/1049732305276687.

15. Mason L, Glenn S, Walton I, et al. Do women practise pelvic floor exercises during pregnancy or following delivery? Physiotherapy 2001; 87:662-670.

16. Mason L, Glenn S, Walton I, et al. The instruction in pelvic floor exercises provided to women during pregnancy or following delivery. Midwifery 2001; 17:55-64.

doi:10.1054/midw.2000.0235.

17. Ashworth PD, Hagan MT. Some social consequences of non-compliance with pelvic floor exercises. Physiotherapy 1993; 79:465-471.

18. Hay-Smith EJC, Ryan K, Dean S. The silent, private exercise: Experiences of pelvic floor muscle training in a sample of women with stress urinary incontinence. Physiotherapy 2007; 93:53-61. 
19. van den Muijsenbergh METC, Lagro-Janssen TALM. Urinary incontinence in Moroccan and Turkish women: A qualitative study on impact and preferences for treatment. Br J Gen Pract 2006; 56:945-949.

20. Kincade JE, Johnson TM, Ashford-Works C, et al. A pilot study to determine reasons for patient withdrawal from a pelvic muscle rehabilitation program for urinary incontinence. J Appl Gerontol 1999; 18:379-396. doi:10.1177/073346489901800307.

21. MacInnes C. Why women leave therapy for stress incontinence. Nurs Times 2008; 104:5053.

22. Milne JL, Moore KN. Factors impacting self-care for urinary incontinence. Urol Nurs 2006; 26:41-51.

23. Gillard S, Shamley D. Factors motivating women to commence and adhere to pelvic floor muscle exercises following a perineal tear at delivery: The influence of experience. J Assoc Chartered Physiother Womens Health 2010; 106:5-18.

24. Chiarelli P, Cockburn J. The development of a physiotherapy continence promotion program using a customer focus. Aust J Physiother 1999; 45:111-119.

25. Sandelowski M. Whatever happened to qualitative description? Res Nurs Health 2000; 23:334-340.

26. Braun V, Clarke V. Using thematic analysis in psychology. Qual Res Psychol 2006; 3:77-101.

27. McClurg D, Frawley H, Dean S, et al. Scoping review of adherence promotion theories in pelvic floor muscle training-2011 ICS State-of-the-Science Seminar Research Paper I of IV. Submitted to Neurourol \& Urodynamics, 2014.

28. Broome BAS. Psychometric analysis of the Broome Pelvic Muscle Self-Efficacy Scale in African-American women with incontinence. Urol Nurs 2001; 21:289-297.

29. Sacomori C, Cardoso FL, Porto IP, et al. The development and psychometric evaluation of a self-efficacy scale for practicing pelvic floor exercises. Braz J Phys Ther 2013; 17:336-342.

30. Chen S-Y. The development and testing of the Pelvic Floor Muscle Exercise Self-Efficacy Scale. J Nurs Res 2004; 12:257-265.

31. Sarma S, Hawthorne G, Thakkar K, et al. The development of an incontinence treatment motivation questionnaire for patients undergoing pelvic floor physiotherapy in the treatment of stress incontinence. Int Urogynecol J 2009; 20:1085-1093.

32. Michie S, van Stralen MM, West R. The behaviour change wheel: A new method for characterising and designing behaviour change interventions. Implement Sci 2011; 6:42. 
33. Michie S, West R. Behaviour change theory and evidence: A presentation to Government. Health Psychol Rev 2013; 7:1-22. doi:10.1080/17437199.2011.649445

34. Hall AM, Ferreira PH, Maher CG, et al. The influence of the therapist-patient relationship on treatment outcome in physical rehabilitation: A systematic review. Phys Ther 2010; 90:10991110.

This is the accepted version of the following article: Hay Smith EJ, Dean S, Burgio K, McClurg D, Frawley H, Dumoulin C. (2015) Pelvic-Floor-Muscle-Training Adherence 'Modifiers': a review of primary qualitative studies - 2011 ICS State-of-the-Science Seminar Research Paper III of IV. Neurourol \& Urodynamics, 2015 May 21; 34(7): 622-631. doi: 10.1002/nau.22771., which has been published in final form at http://onlinelibrary.wiley.com/doi/10.1002/nau.22771/epdf 